\title{
A Rough VIKOR-Based QFD for Prioritizing Design Attributes of Product-Related Service
}

\author{
Xiuzhen $\mathrm{Li}^{1}$ and Wenyan Song ${ }^{2}$ \\ ${ }^{1}$ School of Mechanical Engineering, Shanghai Jiao Tong University, Shanghai 200240, China \\ ${ }^{2}$ School of Economics and Management, Beihang University, Beijing 100191, China \\ Correspondence should be addressed to Wenyan Song; 198212swy@163.com
}

Received 5 April 2016; Revised 16 September 2016; Accepted 28 September 2016

Academic Editor: Ibrahim Zeid

Copyright (C) $2016 \mathrm{X}$. Li and W. Song. This is an open access article distributed under the Creative Commons Attribution License, which permits unrestricted use, distribution, and reproduction in any medium, provided the original work is properly cited.

\begin{abstract}
Many manufacturers today are striving to offer high value-added product-related services (PRS) due to increasing competition and environmental pressure. PRS can reduce the negative impact on the environment, because it extends the life of products and minimizes the cost. Product and service planning has been considered as the critical factor to the success of PRS. Quality function deployment (QFD) has been recognized as an efficient planning tool which can convert customer needs (CNs) into design attributes of PRS involving product attributes (PAs) and service attributes (SAs). However, the subjective and vague information in the design of PRS with QFD may lead to inaccurate priority of PAs and SAs. To solve this problem, a novel rough VIKOR(VIseKriterijumska Optimizaciji I Kompromisno Resenje-) based QFD is proposed. The proposed approach integrates the strength of rough number (RN) in manipulating vague concepts with less a priori information and the merit of VIKOR in structuring framework of compromise decision-making. Finally, an application in compressor-based service design is presented to illustrate the potential of the proposed method.
\end{abstract}

\section{Introduction}

Product-related services (PRS) are services that are closely associated with goods in products. Expanding the service content of products has been for years a major trend in business strategy $[1-3]$. The physical goods are more and more associated with complex services that enhance the product value for customers and provide interesting business models for producers [4]. Besides, PRS can minimize the cost for long-lasting, well-functioning products and aim to sustain a balance between environmental, economic, and social dimensions [5]. Developing PRS is therefore a major concern for firms in a wide range of industries. To ensure the success of PRS, it is necessary to satisfy various customer needs (CNs). Quality function deployment (QFD) is often used to translate CNs into technical attributes (TAs) of product $[6,7]$. However, the prioritizing TAs in the conventional QFD contain vagueness and impreciseness (e.g., linguistic judgments on the $\mathrm{CN}$ importance and the CN-TA relationships) which will affect the accuracy of the TA importance. Furthermore, compared with product design, the design of PRS always links to vague customer perception and subjective experience. This makes the conventional QFD not suitable for prioritizing design attributes of PRS which include product attributes (PAs) and service attributes (SAs). Some researchers have applied the fuzzy set theory to improve conventional QFD, for example, computation using fuzzy variables $[8,9]$, fuzzy integral [10], and fuzzy goal programming [11]. However, fuzzy QFD has been criticized for the pre-set membership function, the fixed fuzzy interval, and the inefficiency in manipulating vague and subjective information. Thus, the conventional QFD and fuzzy QFD cannot effectively deal with the vague prioritization process of PAs and SAs in PRS design.

To solve the above problems, this work proposes a new approach for prioritizing PAs and SAs of PRS by integrating VIKOR (VIseKriterijumska Optimizaciji I Kompromisno Resenje) and rough number (RN). In the rough QFD, the relationships among CNs, PAs, and SAs are mapped, and VIKOR and RN are used to convert the rough $\mathrm{CN}$ importance into the rough PA importance and then into the rough SA 
importance. Thus, designers can make reasonable decisions with vague, subjective, and limited information.

The rest of this paper is organized as follows. Section 2 briefly reviews the related work; Section 3 introduces the framework and the detailed steps of the proposed rough VIKOR-based QFD approach. Section 4 uses a case of air compressor service design to illustrate the proposed method. Comparisons and discussions are also made in this section; Section 5 concludes the research.

\section{Related Work}

2.1. QFD in Service Design. Some researchers have applied the conventional QFD to the field of service design. An et al. [12] developed an integrated product service roadmap with QFD. Lin and Pekkarinen [13] proposed a framework of QFD-based logistics service design to integrate the house of quality (HOQ) technique and modular logic to help in designing logistics services with high quality. In J. A. Fitzsimmons and M. J. Fitzsimmons [14], QFD is used to match the process between service factors and CNs. Li et al. [15] applied QFD to map CNs to service function and map the relationships between product function and structure. Geum et al. [16] modified and applied HOQ to offer a service-focused modularization method. The relationships between module drivers and decomposed service components were analyzed in the Strategic Modularability Matrix (SMM), whereas the interrelationships among service components are identified in Interrelated Components Modularability Matrix (ICMM). Selen and Schepers [17] implemented a service QFD analysis at a federal police station in Belgium that could match the demands and needs of the general public and authorities to the activities deployed by the police service. Chen and Chou [18] integrated Grey Relational Analysis (GRA) into QFD to improve service techniques for an academic library. In conventional QFD, determining the weights of WHATs and HOWs and the relationships between the WHATs and HOWs is an art. But the decision-making information in the conventional QFD is usually expressed in form of experts' linguistic judgements which are subjective or vague [19]. This may lead to the final analysis results being inaccurate.

Therefore, to deal with vague and subjective information in the conventional QFD for service design, the fuzzy set theory is utilized. Geng et al. [20] improved fuzzy QFD for product service system planning. First, they used the fuzzy pairwise comparison to obtain the initial weights of engineering characteristics considering CNs. After that, they applied the data envelopment analysis (DEA) approach to obtain the final weights of engineering characteristics. Song et al. [21] proposed a QFD based on rough-grey relational analysis approach to prioritize the design attributes. In order to identify the critical determinants relating to customer satisfaction, $\mathrm{Su}$ and Lin [22] analyzed the correlation between the imprecise requirements from customers and the determinants of service quality with fuzzy QFD. Bottani [23] proposed an approach to manage customer service based on fuzzy QFD. Fuzzy logic is also adopted to handle the ill-defined nature of the qualitative linguistic judgments required in the fuzzy QFD. Ding [24] applied a fuzzy QFD model to identify solutions of service delivery system (SDS) for a port from the viewpoints of customers. Although fuzzy QFD uses fuzzy number to deal with vague information in service design, its inherent deficiencies will influence the final results in the QFD analysis. For example, fuzzy interval indicating the estimation range may be enlarged after fuzzy arithmetic operations [25], which have impact on the result of QFD. Besides, the membership functions in the fuzzy QFD are usually subjectively and intuitively selected by experts with experience [26].

2.2. Rough Set Theory. Pawlak [27] proposed the rough set theory (RST) and considered it as an effective tool to cope with subjective and vague information even if the data distribution is unknown. Pawlak [28] considered that each vague concept can be represented with a pair of precise concepts using the lower and upper approximations in RST. Assume that there is a set of $n$ classes of human judgments, $R=$ $\left\{J_{1}, J_{2}, \ldots, J_{n}\right\}$, ordered in the manner of $J_{1}<J_{2}<\cdots<J_{n}$, and $Y$ is an arbitrary object of $U$; then the lower approximation of $J_{i}$, the upper approximation of $J_{i}$, and boundary region are defined [29].

Lower approximation:

$$
\underline{\operatorname{Apr}}\left(J_{i}\right)=\bigcup\left\{Y \in U \mid R(Y) \leq J_{i}\right\}
$$

Upper approximation:

$$
\overline{\operatorname{Apr}}\left(J_{i}\right)=\bigcup\left\{Y \in U \mid R(Y) \geq J_{i}\right\} .
$$

Boundary region:

$$
\begin{aligned}
\operatorname{Bnd}\left(J_{i}\right)= & \bigcup\left\{Y \in U \mid R(Y) \neq J_{i}\right\} \\
= & \left\{Y \in U \mid R(Y)>J_{i}\right\} \\
& \cup\left\{Y \in U \mid R(Y)<J_{i}\right\} .
\end{aligned}
$$

For a concept $J_{i}$, the greatest definable set contained in the concept is called the lower approximation of $J_{i}$. The least definable set that contained concept $J_{i}$ is called the upper approximation of $J_{i}$. Elements belonging only to the upper approximation compose the boundary region.

Zhai et al. [25] proposed that the class $J_{i}$ can be represented by a RN, which is defined by its lower $\operatorname{limit} \underline{\operatorname{Lim}}\left(J_{i}\right)$ and upper limit $\overline{\operatorname{Lim}}\left(J_{i}\right)$. The calculation principles are as follows [30]:

$$
\begin{aligned}
& \underline{\operatorname{Lim}}\left(J_{i}\right)=\left[\prod_{k=1}^{N_{L}} R(Y) \mid Y \in \underline{\operatorname{Apr}}\left(J_{i}\right)\right]^{1 / N_{L}}, \\
& \overline{\operatorname{Lim}}\left(J_{i}\right)=\left[\prod_{k=1}^{N_{U}} R(Y) \mid Y \in \overline{\operatorname{Apr}}\left(J_{i}\right)\right]^{1 / N_{U}},
\end{aligned}
$$

where $N_{L}$ and $N_{U}$ are the number of objects included in the lower approximation and upper approximation of $C_{i}$, respectively. The human judgments can be represented by RNs on the basis of lower limit $\left(\underline{\operatorname{Lim}}\left(J_{i}\right)\right)$ and upper limit 
$\left(\overline{\operatorname{Lim}}\left(J_{i}\right)\right)$. The $\mathrm{RN}$ and interval of boundary region are expressed by the following equations:

Rough number:

$$
\mathrm{RN}\left(J_{i}\right)=\left[\overline{\operatorname{Lim}}\left(J_{i}\right), \underline{\operatorname{Lim}}\left(C_{i}\right)\right] .
$$

Interval of boundary region:

$$
\operatorname{IBR}\left(J_{i}\right)=\overline{\operatorname{Lim}}\left(J_{i}\right)-\underline{\operatorname{Lim}}\left(J_{i}\right) .
$$

The arithmetic operations of interval analysis can also be used in RNs as follows [25, 30].

2.3. VIKOR Method. VIKOR (VIseKriterijumska Optimizaciji I Kompromisno Resenje) is an effective tool in multicriteria decision-making (MCDM). It is proposed by Opricovic [31] who introduced the multicriteria ranking index to determine the compromise ranking-list. The alternatives are ranked by comparing the measure of closeness to the ideal solution [32]. VIKOR is developed from the $L_{p}$-metric in compromise programming:

$$
\begin{array}{r}
L_{p, i}=\left[\sum_{j=1}^{m}\left(\omega_{j} \times \frac{f_{j}^{*}-f_{i j}}{f_{j}^{*}-f_{j}^{-}}\right)^{p}\right]^{1 / p}, \\
1 \leq p \leq \infty ; i=1,2,3, \ldots, n,
\end{array}
$$

where $L_{p, i}$ is an aggregating function, $\omega_{j}$ is the weight of the $j$ th criterion, $f_{i j}$ is the evaluation value of the $j$ th criterion for the $i$ th alternative, $f_{j}^{*}$ and $f_{j}^{-}$are the best and worst values of the $j$ th criterion, respectively, and $m$ and $n$ are the numbers of criteria and alternatives, respectively.

In the VIKOR method, $L_{1, i}$ is defined as $S_{i}$ and $L_{\infty, i}$ is defined as $R_{i}$, which are used to formulate ranking measure. While the optimal compromise solution is determined, a maximum group utility $\left(\min _{i=1}^{n} S_{i}\right)$ of the majority and a minimum individual regret $\left(\min _{i=1}^{n} R_{i}\right)$ of the opponent are also considered.

The VIKOR method is suitable for the situation where the decision-maker is not able, or does not know, to express his/her preference at the early stage of solution selection [33]. The ranking order of solutions is determined by the aggregating function $Q$ in which the formats of inputs and outputs are identical. For example, the inputs are interval numbers, and the outputs are also interval numbers. However, in the TOPSIS, no matter whether the inputs are precise numbers or interval numbers, the outputs are precise numbers. If the outputs of a process are the new inputs of the next process (e.g., QFD) and the original inputs are interval numbers, the result from TOPSIS is inaccurate because the original inputs are interval numbers and the new inputs are precise numbers. VIKOR can deal with this problem. Therefore, the VIKOR method is widely used in industry.

Although VIKOR is a simple and straightforward MCDM technique, it cannot well reflect the vague and subjective information contained in the process of QFD analysis for PRS; that is, it lacks the capability of capturing and reflecting the subjective perceptions of designers in the analyzing process. Thus, a new method should be developed to effectively manipulate the vague and subjective information in the QFD.

\section{The Proposed Rough VIKOR-Based QFD Method}

In order to solve the problem of vagueness and subjectivity in the early design of PRS, a QFD framework based on rough VIKOR is proposed, as shown in Figure 1. The proposed method is composed of two phases. The first phase is to identify CNs, PAs, and SAs. CNs are classified, PAs are selected to satisfy CNs, and SAs are identified to ensure the normal operation of PAs. The second phase is to calculate the importance of PAs and SAs. Customers evaluate the $\mathrm{CN}$ importance, and experts judge the CN-PA relationships and PA-SA relationships. These crisp ratings are then converted into RNs. Individual RNs are aggregated to generate group RNs. The group rough importance and relationships are normalized. Based on the $\mathrm{CN}$ importance and CN-PA relationships, the PA importance is calculated and prioritized by the proposed rough VIKOR. Similarly, the SA importance is also calculated and ranked based on the PA importance and PA-SA relationships.

3.1. Analyze CNs, PAs, and SAs. In order to improve customer satisfaction of new products, CNs are collected and classified. Meanwhile, experts identify PAs and SAs.

3.1.1. Classify CNs. CNs are the crucial inputs for the success of new product development. $\mathrm{A} \mathrm{CN}$ is a description, in the customer's own words, of the benefit to be fulfilled by the product or service [34]. Usually, CNs are too general or too detailed to be directly used for new product development. Some tools and methods are chosen to classify CNs, such as an affinity diagram [35], Kano model [36], and Maslow model [37]. In this paper, CNs of PRS are identified with the method of I-CAC (Industrial customer activity analysis cycle) proposed in Song et al. [38]. The identification method of I-CAC can systematically consider the full stages of CNs. Because of the limited space here, the specific methods are not repeated. Interested readers are encouraged to read the work of Song et al. [38]. Here, CNs are denoted as follows:

$$
\mathrm{CN}=\left\{\mathrm{CN}_{1}, \mathrm{CN}_{2}, \mathrm{CN}_{3}, \ldots, \mathrm{CN}_{i}, \ldots, \mathrm{CN}_{m}\right\},
$$

where $\mathrm{CN}_{i}$ represents the $i$ th $\mathrm{CN}$ for new product, $m$ is the number of CNs. $\forall \mathrm{CN}_{i}, \mathrm{CN}_{j}, \exists \mathrm{CN}_{i} \cap \mathrm{CN}_{j}=\varnothing(i \neq j)$.

3.1.2. Identify PAs and SAs. To satisfy CNs, PAs are identified. Then SAs are also identified to improve the design. They are expressed as follows:

$$
\begin{aligned}
& \mathrm{PA}=\left\{\mathrm{PA}_{1}, \mathrm{PA}_{2}, \mathrm{PA}_{3}, \ldots, \mathrm{PA}_{i}, \ldots, \mathrm{PA}_{n}\right\}, \\
& \mathrm{SA}=\left\{\mathrm{SA}_{1}, \mathrm{SA}_{2}, \mathrm{SA}_{3}, \ldots, \mathrm{SA}_{i}, \ldots, \mathrm{SA}_{k}\right\},
\end{aligned}
$$

where $\mathrm{PA}_{i}$ represents the $i$ th $\mathrm{PA}$ of new product, $n$ is the number of PAs, $\mathrm{SA}_{i}$ represents the $i$ th $\mathrm{SA}$ of new product, and $k$ is the number of SAs. $\forall \mathrm{TA}_{i}, \mathrm{TA}_{j}, \exists \mathrm{TA}_{i} \cap \mathrm{TA}_{j}=\varnothing(i \neq j)$, and, $\forall \mathrm{SA}_{i}, \mathrm{SA}_{j}, \exists \mathrm{SA}_{i} \cap \mathrm{SA}_{j}=\varnothing(i \neq j)$.

3.2. Calculate the Importance of PAs and SAs. In the rough QFD, the importance of PAs and SAs is calculated by integrating VIKOR and RN. The process is as follows. 


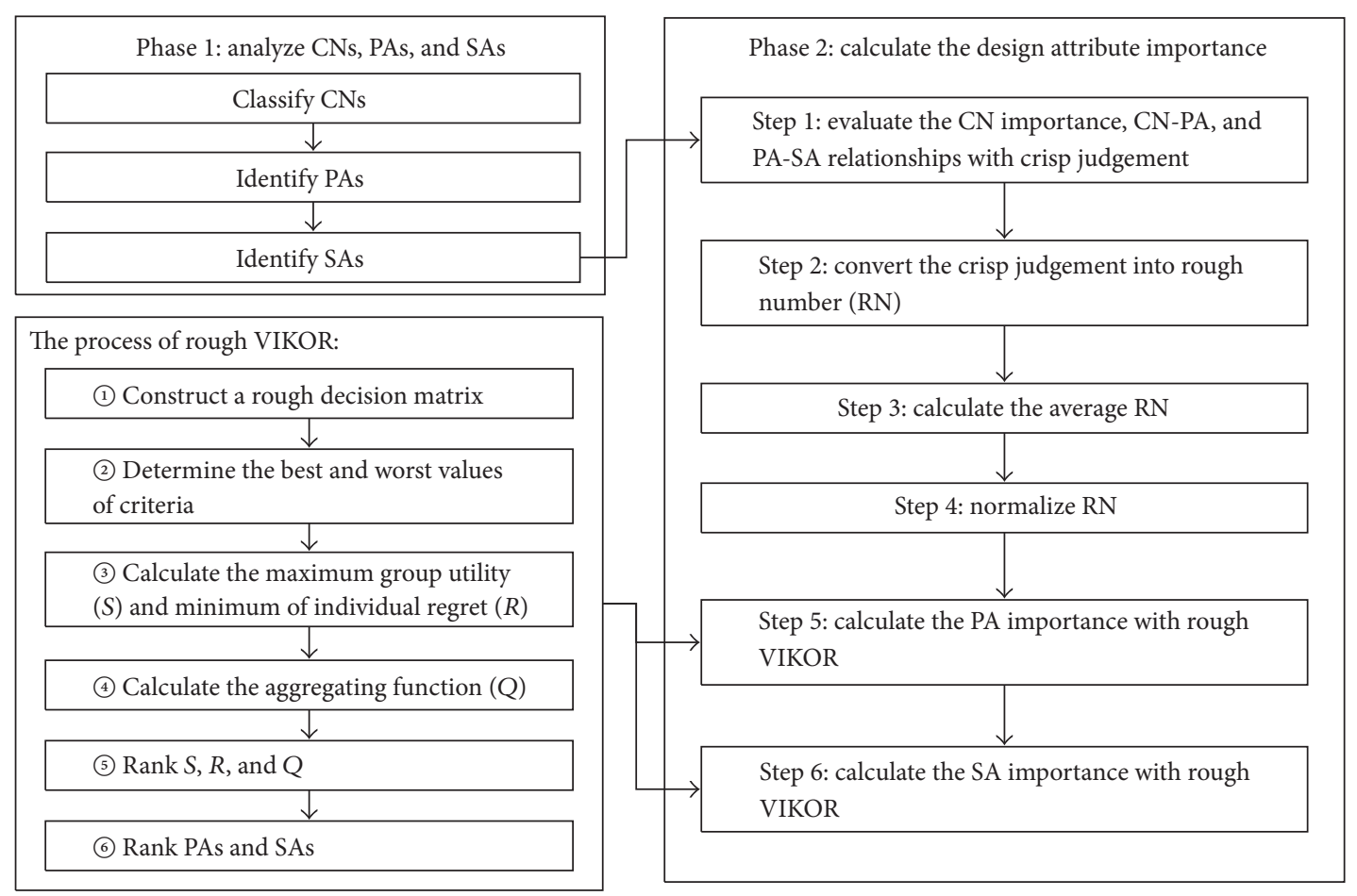

FIGURE 1: The proposed QFD framework based on rough VIKOR.

Step 1 (evaluate the $\mathrm{CN}$ importance, the $\mathrm{CN}-\mathrm{PA}$ relationships, and PA-SA relationships with crisp judgment). Customers evaluate the $\mathrm{CN}$ importance with the 9-point subscale (13-5-7-9). Scores of 1, 3, 5, 7, and 9 are define as very low, low, moderate, high, and very high importance, respectively. Similarly, experts evaluate the CN-PA relationship and the PA-SA relationship with the 9-point subscale. Scores of 1, $3,5,7$, and 9 represent very weak, weak, moderate, strong, and very strong relationship. The $\mathrm{CN}$ importance, the CN-PA relationship, and the PA-SA relationship are obtained.

$$
\begin{aligned}
& \omega_{i}=\left\{\omega_{i}^{1}, \omega_{i}^{2}, \omega_{i}^{3}, \ldots, \omega_{i}^{h}, \ldots, \omega_{i}^{H}\right\}, \\
& r_{i j}=\left\{r_{i j}^{1}, r_{i j}^{2}, r_{i j}^{3}, \ldots, r_{i j}^{l}, \ldots, r_{i j}^{L}\right\},
\end{aligned}
$$

where $\omega_{i}^{h}$ represents the $h$ th customer's evaluation on the importance of the $i$ th $\mathrm{CN}, H$ is the number of customers, $r_{i j}^{l}$ represents the $l$ th expert's evaluation on the relationship between the $i$ th $\mathrm{CN}$ and the $j$ th PA or the $i$ th PA and the $j$ th $\mathrm{SA}$, and $L$ is the number of experts.

Step 2 (convert the crisp judgement into $\mathrm{RN}$ ). The crisp importance and crisp relationships are converted into RNs with formula (4).

$$
\begin{aligned}
& \operatorname{RN}\left(\omega_{i}^{k}\right)=\left[\omega_{i}^{h L}, \omega_{i}^{h U}\right], \\
& \operatorname{RN}\left(r_{i j}^{s}\right)=\left[r_{i j}^{l L}, r_{i j}^{l U}\right],
\end{aligned}
$$

where $\omega_{i}^{h L}$ and $r_{i j}^{l L}$ are the lower limits of RNs and $\omega_{i}^{h U}$ and $r_{i j}^{l U}$ are the upper limits of RNs.
Step 3 (aggregate individual $\mathrm{RN}$ to generate group $\mathrm{RN}$ ). The group $\mathrm{RN}$ is aggregated as follows:

$$
\begin{aligned}
& \omega_{i}^{L}=\sqrt[H]{\prod_{h=1}^{H} \omega_{i}^{h L},} \\
& \omega_{i}^{U}=\sqrt[H]{\prod_{h=1}^{H} \omega_{i}^{h U}}, \\
& r_{i j}^{L}=\sqrt[s]{\prod_{s=1}^{S} r_{i j}^{s L}} \\
& r_{i j}^{U}=\sqrt[s]{\prod_{s=1}^{S} r_{i j}^{s U} .}
\end{aligned}
$$

Step 4 (normalize the rough importance and rough relationships). The rough importance and rough relationships are normalized as follows:

$$
\begin{aligned}
\omega_{i}^{\prime L} & =\frac{\omega_{i}^{L}}{\max _{i=1}^{m}\left\{\max \left[\omega_{i}^{L}, \omega_{i}^{U}\right]\right\}}, \\
\omega_{i}^{\prime U} & =\frac{\omega_{i}^{U}}{\max _{i=1}^{m}\left\{\max \left[\omega_{i}^{L}, \omega_{i}^{U}\right]\right\}}, \\
f_{i j}^{L} & =\frac{r_{i j}^{L}}{\max _{j=1}^{n}\left\{\max \left[r_{i j}^{L}, r_{i j}^{U}\right]\right\}}, \\
f_{i j}^{U} & =\frac{r_{i j}^{U}}{\max _{j=1}^{n}\left\{\max \left[r_{i j}^{L}, r_{i j}^{U}\right]\right\}} .
\end{aligned}
$$


Step 5 (calculate the PA importance with rough VIKOR). The importance of PAs is calculated with rough VIKOR as follows [39].

(1) Construct a Rough Decision Matrix D. The CN-PA relationships are defined as the alternatives, and the importance of CNs is the evaluation criterion. The rough decision matrix $D$ is

$$
D=\left[\begin{array}{cccc}
{\left[f_{11}^{L}, f_{11}^{U}\right]} & {\left[f_{12}^{L}, f_{12}^{U}\right]} & \cdots & {\left[f_{1 m}^{L}, f_{1 m}^{U}\right]} \\
{\left[f_{21}^{L}, f_{21}^{U}\right]} & {\left[f_{22}^{L}, f_{22}^{U}\right]} & \cdots & {\left[f_{2 m}^{L}, f_{2 m}^{U}\right]} \\
\vdots & \vdots & \vdots & \vdots \\
{\left[f_{n 1}^{L}, f_{n 1}^{U}\right]} & {\left[f_{n 2}^{L}, f_{n 2}^{U}\right]} & \cdots & {\left[f_{n m}^{L}, f_{n m}^{U}\right]}
\end{array}\right] .
$$

(2) Determine the Best $f_{j}^{+}$and Worst $f_{j}^{-}$. For the benefit criterion, the larger the value of $f_{j}$ is, the better the result is. For the cost criterion, the smaller the value of $f_{j}$ is, the better the result is.

$$
\begin{aligned}
& f_{j}^{+}=\max _{j \in B}^{n} f_{i j}^{U} \text { or } \min _{j \in C}^{n} f_{i j}^{L}, \\
& f_{j}^{-}=\min _{j \in B}^{n} f_{i=1}^{L} \text { or } \max _{j \in C}^{n} f_{i=1}^{U},
\end{aligned}
$$

where $B$ is associated with the benefit criterion and $C$ is associated with the cost criterion.

(3) Calculate $S_{i}$ and $R_{i} . S$ and $R$ are calculated as follows:

$$
\begin{aligned}
& S_{i}^{L}=\sum_{j \in B} \omega_{j}^{L L} \frac{f_{j}^{+}-f_{i j}^{U}}{f_{j}^{+}-f_{j}^{-}}+\sum_{j \in C} \omega_{j}^{L L} \frac{f_{i j}^{L}-f_{j}^{+}}{f_{j}^{-}-f_{j}^{+}}, \\
& S_{i}^{U}=\sum_{j \in B} \omega_{j}^{\prime U} \frac{f_{j}^{+}-f_{i j}^{L}}{f_{j}^{+}-f_{j}^{-}}+\sum_{j \in C} \omega_{j}^{\prime U} \frac{f_{i j}^{U}-f_{j}^{+}}{f_{j}^{-}-f_{j}^{+}}, \\
& R_{i}^{L}=\max _{j \in B}^{m} \omega_{j=1}^{\prime L} \frac{f_{j}^{+}-f_{i j}^{U}}{f_{j}^{+}-f_{j}^{-}} \text {or } \max _{j \in C}^{m} \omega_{j=1}^{\prime L} \frac{f_{i j}^{L}-f_{j}^{+}}{f_{j}^{-}-f_{j}^{+}}, \\
& R_{i}^{U}=\max _{j \in B}^{m} \omega_{j=1}^{\prime U} \frac{f_{j}^{+}-f_{i j}^{L}}{f_{j}^{+}-f_{j}^{-}} \text {or } \max _{j \in C}^{m} \omega_{j=1}^{\prime U} \frac{f_{i j}^{U}-f_{j}^{+}}{f_{j}^{-}-f_{j}^{+}} .
\end{aligned}
$$

(4) Calculate the Aggregating Function $Q_{i}$. Consider the following:

$$
\begin{aligned}
& Q_{i}^{L}=v \frac{S_{i}^{L}-S^{+}}{S^{-}-S^{+}}+(1-v) \frac{R_{i}^{L}-R^{+}}{R^{-}-R^{+}}, \\
& Q_{i}^{U}=v \frac{S_{i}^{U}-S^{+}}{S^{-}-S^{+}}+(1-v) \frac{R_{i}^{U}-R^{+}}{R^{-}-R^{+}},
\end{aligned}
$$

where $S^{+}=\min _{i=1}^{n} S_{i}^{L}, S^{-}=\max _{i=1}^{n} S_{i}^{U}, R^{+}=\min _{i=1}^{n} R_{i}^{L}, R^{-}=$ $\max _{i=1}^{n} R_{i}^{U}, v$ is the weight of the strategy of the majority of criteria $(v \in[0,1])$, and usually $v=0.5$.

(5) Rank $S, R$, and $Q$. S, R, and $Q$ are ranked in decreasing order. So three ranking lists are obtained.
For any two interval numbers $[\underline{\operatorname{Lim}}(\alpha), \overline{\operatorname{Lim}}(\alpha)]$ and $[\underline{\operatorname{Lim}}(\beta), \overline{\operatorname{Lim}}(\beta)]$, the ranking rule is described as follows.

(a) If the interval of a $\mathrm{RN}$ is not strictly contained by another

(i) if $\underline{\operatorname{Lim}}(\beta) \geq \underline{\operatorname{Lim}}(\alpha)$ and $\overline{\operatorname{Lim}}(\beta)>\overline{\operatorname{Lim}}(\alpha)$, or $\underline{\operatorname{Lim}}(\beta)>\underline{\operatorname{Lim}}(\alpha)$ and $\overline{\operatorname{Lim}}(\beta) \geq \overline{\operatorname{Lim}}(\alpha)$, then $\mathrm{RN}(\beta)>\overline{\mathrm{RN}}(\alpha)$, where " $>$ " means "more important than";

(ii) if $\underline{\operatorname{Lim}}(\beta)=\underline{\operatorname{Lim}}(\alpha)$ and $\overline{\operatorname{Lim}}(\beta)=\overline{\operatorname{Lim}}(\alpha)$, then $\operatorname{RN}(\beta)=\operatorname{RN}(\alpha)$.

(b) If the interval of a $\mathrm{RN}$ is strictly contained by another

(i) if $\underline{\operatorname{Lim}}(\beta)>\underline{\operatorname{Lim}}(\alpha)$ and $\overline{\operatorname{Lim}}(\beta)<\overline{\operatorname{Lim}}(\alpha)$

if $M(\beta) \leq M(\alpha)$, then $\mathrm{RN}(\beta) \prec \mathrm{RN}(\alpha)$, where $M(\alpha)$ and $M(\beta)$ are the median of $\mathrm{RN}(\alpha)$ and $\mathrm{RN}(\beta)$, respectively; if $M(\beta)>M(\alpha)$, then $\mathrm{RN}(\beta)>\mathrm{RN}(\alpha)$.

(ii) If $\underline{\operatorname{Lim}}(\beta)<\underline{\operatorname{Lim}}(\alpha)$ and $\overline{\operatorname{Lim}}(\beta)>\overline{\operatorname{Lim}}(\alpha)$

if $M(\beta) \leq M(\alpha)$, then $\mathrm{RN}(\beta) \prec \mathrm{RN}(\alpha)$; if $M(\beta)>M(\alpha)$, then $\mathrm{RN}(\beta)>\mathrm{RN}(\alpha)$.

6 Rank PAs. Assume that $\mathrm{PA}_{i}$ is ranked the best by calculating $Q$ (minimum), if the following two conditions are satisfied:

$\left(\mathrm{C}_{1}\right)$ Acceptable advantage:

$$
\begin{aligned}
& \sqrt{\frac{\left[\mathrm{Q}^{L}\left(\mathrm{PA}_{j}\right)-\mathrm{Q}^{L}\left(\mathrm{PA}_{i}\right)\right]^{2}+\left[\mathrm{Q}^{U}\left(\mathrm{PA}_{j}\right)-\mathrm{Q}^{U}\left(\mathrm{PA}_{i}\right)\right]^{2}}{2}} \\
& \quad \geq \frac{1}{n-1},
\end{aligned}
$$

where $\mathrm{PA}_{j}$ is the second $\mathrm{PA}$ ranked by calculating $\mathrm{Q}$.

$\left(\mathrm{C}_{2}\right)$ Acceptable stability in decision-making: $\mathrm{PA}_{i}$ must also be ranked the best by calculating $S$ or/and $R$. This compromise solution is stable in the decision-making process. When $v>0.5$, it could be the strategy of maximum group utility, or "by consensus" ( $v \approx 0.5)$, or "with veto" $(v<0.5)$ follows:

If $\left(\mathrm{C}_{1}\right)$ or $\left(\mathrm{C}_{2}\right)$ is not satisfied, a set of PAs is proposed as

(1) $\mathrm{PA}_{i}$ and $\mathrm{PA}_{j}$ if only $\left(\mathrm{C}_{2}\right)$ is not satisfied,

(2) $\mathrm{PA}_{i}, \mathrm{PA}_{j}, \ldots, \mathrm{PA}_{s}$ if $\left(\mathrm{C}_{1}\right)$ is not satisfied. $\mathrm{PA}_{s}$ is calculated by

$\sqrt{\frac{\left[\mathrm{Q}^{L}\left(\mathrm{PA}_{s}\right)-\mathrm{Q}^{L}\left(\mathrm{PA}_{i}\right)\right]^{2}+\left[\mathrm{Q}^{U}\left(\mathrm{PA}_{s}\right)-\mathrm{Q}^{U}\left(\mathrm{PA}_{i}\right)\right]^{2}}{2}}$ 
Therefore, the ranking order of PAs is determined by the aggregating function $Q$. However, the smaller the value of $Q$ is, the larger the importance of PA becomes. For example, the median of $Q_{p}$ is the maximum, and the median of $Q_{i}$ is the minimum. The importance of $\mathrm{PA}_{i}$ is $\left[Q_{p}^{L}, Q_{p}^{U}\right]$, and the $\mathrm{PA}_{p}$ importance is $\left[Q_{i}^{L}, Q_{i}^{U}\right]$. The importance of PAs is the key input of calculating the SA importance in the next process of rough QFD.

Step 6 (calculate the SA importance with rough VIKOR). Similarly, the SA-PA relationship matrix is the rough decision matrix, and the PA importance is the evaluation criterion. According to Step 5, the importance of SAs is calculated.

\section{Case Study}

In this section, the design of the compressor-related services is taken as an example to illustrate the application of the proposed method. The compressor is the heart of refrigeration system. It can compress and transport refrigerant vapor and make the refrigerant work. The design of the compressor affects the performance of a refrigerator directly. The information of the compressor is provided by company $\mathrm{A}$, who has developed the compressor for more than 40 years. It mainly provides the compressor and related services to its customers.

4.1. Analyze CNs, PAs, and SAs. Before developing the compressor, a team consisting of 20 investigators in company A take more than two months to collect CNs. These investigators are divided into five groups. Three groups interview key customers, one group communicates with their vendors, and the other exchanges the information of the compressor with the relevant enterprises. After collecting CNs, the team refines them and six key CNs are determined. They are safety $\left(\mathrm{CN}_{1}\right)$, lower energy consumption $\left(\mathrm{CN}_{2}\right)$, lower noise $\left(\mathrm{CN}_{3}\right)$, lower failure rate $\left(\mathrm{CN}_{4}\right)$, being easy to maintain $\left(\mathrm{CN}_{5}\right)$, and environmental protection $\left(\mathrm{CN}_{6}\right)$.

To satisfy the six key CNs, design team identifies PAs of the compressor. In the concurrent and collaborative design, all groups can work together at the same time. For example, one group involving 25 persons designs the parts or components, one group including 10 people develops the power system, and another group consisting of 8 people designs the hydraulic system. According to the existing knowledge, experience, and CNs, these designers exchange the information and then identify seven key PAs, that is, refrigerating capacity $\left(\mathrm{PA}_{1}\right)$, cylinder volume $\left(\mathrm{PA}_{2}\right)$, rated power $\left(\mathrm{PA}_{3}\right)$, performance coefficient $\left(\mathrm{PA}_{4}\right)$, structure $\left(\mathrm{PA}_{5}\right)$, noise $\left(\mathrm{PA}_{6}\right)$, and air discharge $\left(\mathrm{PA}_{7}\right)$. Similarly, service team consisting of 22 people identify SAs to improve the design of the compressor. Seven key SAs are determined depending on the existing knowledge, CNs, PAs, and so forth. The final determined SAs are diagnosing failure timely $\left(\mathrm{SA}_{1}\right)$, less repair time $\left(\mathrm{SA}_{2}\right)$, lower repair cost $\left(\mathrm{SA}_{3}\right)$, supplying spare parts timely $\left(\mathrm{SA}_{4}\right)$, supplying spare parts with lower cost $\left(\mathrm{SA}_{5}\right)$, professional cleaning $\left(\mathrm{SA}_{6}\right)$, and timely lubrication $\left(\mathrm{SA}_{7}\right)$.
TABLE 1: The crisp ratings for the $\mathrm{CN}$ importance.

\begin{tabular}{lccccc}
\hline $\mathrm{CN}$ & $\mathrm{C} 1$ & $\mathrm{C} 2$ & $\mathrm{C} 3$ & $\mathrm{C} 4$ & $\mathrm{C} 5$ \\
\hline $\mathrm{CN}_{1}$ & 9 & 7 & 9 & 9 & 9 \\
$\mathrm{CN}_{2}$ & 5 & 9 & 7 & 7 & 7 \\
$\mathrm{CN}_{3}$ & 5 & 7 & 9 & 5 & 7 \\
$\mathrm{CN}_{4}$ & 7 & 9 & 7 & 9 & 9 \\
$\mathrm{CN}_{5}$ & 3 & 3 & 5 & 3 & 5 \\
$\mathrm{CN}_{6}$ & 5 & 5 & 7 & 5 & 7 \\
\hline
\end{tabular}

4.2. Calculate the PA Importance and SA Importance. The PA importance and SA importance are calculated in the following steps.

Step 1 (evaluate the CN importance, the CN-PA relationships, and PA-SA relationships with crisp judgment). Five key customers are invited to evaluate the $\mathrm{CN}$ importance of the compressor with the 9-point subscale, as shown in Table 1. Similarly, five key experts from the design team evaluate the CN-PA relationships, as shown in Table 2. Note that 0 indicates that $\mathrm{CN}$ and PA and PA and SA are uncorrelated. Then five experts from the service team evaluate the PA-SA relationships, as shown in Table 3.

Step 2 (convert the crisp ratings into RNs). The crisp ratings are converted into RNs with formula (4). For example, the $\mathrm{CN}_{2}$ importance is $\{5,9,7,7,7\}$. $\underline{\operatorname{Lim}}(5)=\sqrt[1]{5}=5, \overline{\operatorname{Lim}}(5)=$ $\sqrt[5]{5 \times 7 \times 7 \times 7 \times 9}=6.88, \underline{\operatorname{Lim}(9)}=\sqrt[5]{9 \times 7 \times 7 \times 7 \times 5}=$ 6.88, $\overline{\operatorname{Lim}}(9)=\sqrt[1]{9}=9, \underline{\operatorname{Lim}(7)}=\sqrt[4]{7 \times 7 \times 7 \times 5}=6.44$, and $\overline{\operatorname{Lim}}(7)=\sqrt[4]{7 \times 7 \times 7 \times 9}=7.45$. The rough importance of $\mathrm{CN}_{2}$ is $\{[5.00,6.88],[6.88,9.00],[6.44,7.45],[6.44,7.45]$, $[6.44,7.45]\}$.

Step 3 (aggregate individual $\mathrm{RN}$ to generate group $\mathrm{RN}$ ). According to (12), the group rough importance and group rough relationships are aggregated. For the rough importance of $\mathrm{CN}_{2}, \underline{\operatorname{Lim}}\left(\omega_{2}\right)=\sqrt[5]{5.00 \times 6.88 \times 6.44 \times 6.44 \times 6.44}=6.20$ and $\overline{\operatorname{Lim}}\left(\omega_{2}\right)=\sqrt[5]{6.88 \times 9.00 \times 7.45 \times 7.45 \times 7.45}=7.61$. The group rough importance of $\mathrm{CN}_{2}$ is $[6.20,7.61]$.

Step 4 (normalize the group rough importance and group rough relationships). The group rough importance and group rough relationships are normalized with formula (13)(14), respectively.

Step 5 (calculate the PA importance with rough VIKOR). According to Step 4, the CN importance is $\{[0.92,1.00],[0.70$, $0.85],[0.63,0.83],[0.86,0.97],[0.37,0.47],[0.59,0.70]\}$, and the rough decision matrix of PAs is determined (shown in Table 4). The best $f^{+}$and worst $f^{-}$are identified with formula (16), as shown in Table 5. $S$ and $R$ are calculated with formulas (17)-(18) and (19)-(20), respectively (see Table 6). $Q$ is calculated with formula (21), as shown in Table 6 . According to (5) and (6) in Section 3.2, the PA importance is determined (see Table 6).

Step 6 (calculate the SA importance with rough VIKOR). Similarly, the rough decision matrix of SAs is determined 
TABLE 2: The crisp ratings for the relationships between CNs and PAs.

\begin{tabular}{lccccccc}
\hline & $\mathrm{PA}_{1}$ & $\mathrm{PA}_{2}$ & $\mathrm{PA}_{3}$ & $\mathrm{PA}_{4}$ & $\mathrm{PA}_{5}$ & $\mathrm{PA}_{6}$ \\
\hline $\mathrm{CN}_{1}$ & $7,3,7,5,5$ & $1,1,1,1,1$ & $5,7,7,5,7$ & $9,7,9,9,9$ & $5,5,5,3,5$ & $3,1,1,3,1$ & $1,1,3,1,1$ \\
$\mathrm{CN}_{2}$ & $9,9,7,9,7$ & $0,0,0,0,0$ & $5,1,3,3,3$ & $7,9,7,7,9$ & $3,1,1,1,1$ & $0,0,0,0,0$ & $3,1,1,3,1$ \\
$\mathrm{CN}_{3}$ & $3,1,3,3,5$ & $0,0,0,0,0$ & $3,3,1,5,1$ & $7,5,7,9,5$ & $5,3,5,7,5$ & $9,9,9,9,9$ & $1,1,1,3,1$ \\
$\mathrm{CN}_{4}$ & $5,5,5,5,3$ & $0,0,0,0,0$ & $3,1,5,3,5$ & $5,3,7,7,7$ & $5,3,3,3,3$ & $1,3,1,3,1$ & $1,3,1,1,1$ \\
$\mathrm{CN}_{5}$ & $0,0,0,0,0$ & $5,3,5,5,3$ & $0,0,0,0,0$ & $0,0,0,0,0$ & $7,5,5,5,3$ & $0,0,0,0,0$ & $0,0,0,0,0$ \\
$\mathrm{CN}_{6}$ & $7,5,5,3,5$ & $0,0,0,0,0$ & $0,0,0,0,0$ & $3,5,3,7,5$ & $3,3,3,1,1$ & $5,1,3,5,3$ & $3,1,3,3,1$ \\
\hline
\end{tabular}

TABLE 3: The crisp ratings for the relationships between PAs and SAs.

\begin{tabular}{lccccccc}
\hline & $\mathrm{SA}_{1}$ & $\mathrm{SA}_{2}$ & $\mathrm{SA}_{3}$ & $\mathrm{SA}_{4}$ & $\mathrm{SA}_{5}$ & $\mathrm{SA}_{6}$ \\
\hline $\mathrm{PA}_{1}$ & $5,3,3,7,5$ & $7,5,5,7,7$ & $5,7,5,7,5$ & $0,0,0,0,0$ & $0,0,0,0,0$ & $1,3,1,3,1$ & $3,1,3,3,1$ \\
$\mathrm{PA}_{2}$ & $1,3,1,5,3$ & $5,5,5,7,5$ & $9,7,9,9,7$ & $3,3,1,3,3$ & $9,5,7,7,5$ & $0,0,0,0,0$ & $0,0,0,0,0$ \\
$\mathrm{PA}_{3}$ & $5,7,5,5,7$ & $7,7,7,7,5$ & $7,5,7,9,7$ & $0,0,0,0,0$ & $0,0,0,0,0$ & $0,0,0,0,0$ & $5,3,5,7,3$ \\
$\mathrm{PA}_{4}$ & $3,3,3,5,3$ & $5,3,5,3,5$ & $5,7,5,5,7$ & $3,1,3,5,3$ & $7,5,5,3,5$ & $7,7,5,5,7$ & $5,5,7,9,7$ \\
$\mathrm{PA}_{5}$ & $5,3,5,5,7$ & $7,5,7,7,7$ & $9,9,9,7,9$ & $5,3,3,3,3$ & $9,7,5,9,7$ & $5,3,5,5,3$ & $5,7,5,7,7$ \\
$\mathrm{PA}_{6}$ & $5,3,1,3,5$ & $3,3,5,5,5$ & $7,5,5,5,3$ & $0,0,0,0,0$ & $0,0,0,0,0$ & $0,0,0,0,0$ & $3,3,7,5,5$ \\
$\mathrm{PA}_{7}$ & $1,5,1,3,3$ & $5,3,5,5,3$ & $5,5,7,3,5$ & $0,0,0,0,0$ & $0,0,0,0,0$ & $5,7,5,7,5$ & $5,7,5,7,3$ \\
\hline
\end{tabular}

TABle 4: The rough decision matrix of PAs.

\begin{tabular}{|c|c|c|c|c|c|c|}
\hline & $\mathrm{CN}_{1}$ & $\mathrm{CN}_{2}$ & $\mathrm{CN}_{3}$ & $\mathrm{CN}_{4}$ & $\mathrm{CN}_{5}$ & $\mathrm{CN}_{6}$ \\
\hline $\mathrm{PA}_{1}$ & {$[0.48,0.69]$} & {$[0.89,1.00]$} & {$[0.22,0.39]$} & {$[0.63,0.75]$} & {$[0.00,0.00]$} & {$[0.74,1.00]$} \\
\hline $\mathrm{PA}_{2}$ & {$[0.11,0.11]$} & {$[0.00,0.00]$} & {$[0.00,0.00]$} & {$[0.00,0.00]$} & {$[0.65,0.83]$} & {$[0.00,0.00]$} \\
\hline $\mathrm{PA}_{3}$ & {$[0.63,0.74]$} & {$[0.23,0.41]$} & {$[0.16,0.35]$} & {$[0.32,0.62]$} & {$[0.00,0.00]$} & {$[0.00,0.00]$} \\
\hline $\mathrm{PA}_{4}$ & {$[0.92,1.00]$} & {$[0.84,0.95]$} & {$[0.63,0.74]$} & {$[0.69,1.00]$} & {$[0.00,0.00]$} & {$[0.64,0.95]$} \\
\hline $\mathrm{PA}_{5}$ & {$[0.46,0.55]$} & {$[0.12,0.17]$} & {$[0.46,0.62]$} & {$[0.47,0.55]$} & {$[0.74,1.00]$} & {$[0.27,0.45]$} \\
\hline $\mathrm{PA}_{6}$ & {$[0.13,0.23]$} & {$[0.00,0.00]$} & {$[1.00,1.00]$} & {$[0.18,0.31]$} & {$[0.00,0.00]$} & {$[0.37,0.73]$} \\
\hline $\mathrm{PA}_{7}$ & {$[0.12,0.17]$} & {$[0.14,0.23]$} & {$[0.12,0.17]$} & {$[0.16,0.23]$} & {$[0.00,0.00]$} & {$[0.27,0.45]$} \\
\hline
\end{tabular}

TABLE 5: The best $f^{+}$and worst $f^{-}$of each criterion (PAs).

\begin{tabular}{lllllll}
\hline & $\mathrm{CN}_{1}$ & $\mathrm{CN}_{2}$ & $\mathrm{CN}_{3}$ & $\mathrm{CN}_{4}$ & $\mathrm{CN}_{5}$ & $\mathrm{CN}_{6}$ \\
\hline$f_{j}^{+}$ & 1.00 & 1.00 & 1.00 & 1.00 & 1.00 & 1.00 \\
$f_{j}^{-}$ & 0.11 & 0.00 & 0.00 & 0.00 & 0.00 & 0.00 \\
\hline
\end{tabular}

(shown in Table 7), the best $f^{+}$and worst $f^{-}$are shown in Table 8, and $S, R$, and $Q$ and the SA importance are shown in Table 9.

4.3. Comparisons and Discussion. To reveal the advantages of the proposed method, the conventional QFD (using precise numbers) and fuzzy QFD (using symmetrical triangular fuzzy numbers) are applied (see Tables 10, 11, and 12). The criteria of comparisons between rough QFD, conventional QFD, and fuzzy QFD are uncertainty manipulation mechanism, prior information requirement, and flexibility.

(1) Comparisons between the Rough QFD and Conventional QFD. The conventional QFD is a systematic and operational method which realizes CNs to drive the product design and production process. The precise numbers are usually adopted to translate "voice of customer" into "voice of technician." The relationship between CNs and PAs is evaluated precisely which can improve customer satisfaction. Therefore, the conventional QFD using the precise numbers is used widely in the product development. However, decision-makers express their perceptions with the vague and subjective information. The precise numbers deal with these information inaccurately. For example, the importance of $\mathrm{PA}_{2}$ is 0.00 in Table 11, and the importance of $\mathrm{SA}_{4}$ is also 0.00 in Table 12. This indicates that $\mathrm{PA}_{2}$ and $\mathrm{SA}_{4}$ should not be considered in the next stage of development. However, this is inconsistent with the expectation of designers in the case company. Actually, the importance of $\mathrm{PA}_{2}$ and $\mathrm{SA}_{4}$ is very low rather than 0.00 . The rough and fuzzy QFD can provide the result in Tables 11 and 12. In this respect, the rough QFD considers vague and subjective information in the product development, and it is more practical than the conventional QFD.

(2) Comparisons between the Rough QFD and Fuzzy QFD. Although the rough and fuzzy QFD handle the vague and subjective information effectively, their mechanisms of dealing with vague and subjective information are different. The 
TABLE 6: The $S, R$, and $Q$ and the weights of PAs.

\begin{tabular}{|c|c|c|c|c|c|c|c|c|}
\hline & \multicolumn{2}{|c|}{$S$} & \multicolumn{2}{|c|}{$R$} & \multicolumn{2}{|c|}{$Q$} & \multirow{2}{*}{ Weight } & \multirow{2}{*}{ Rank } \\
\hline & $S_{i}$ & Rank & $R_{i}$ & Rank & $Q_{i}$ & Rank & & \\
\hline $\mathrm{PA}_{1}$ & {$[1.29,2.32]$} & 2 & {$[0.38,0.65]$} & 2 & {$[0.15,0.44]$} & 2 & {$[0.73,0.96]$} & 2 \\
\hline $\mathrm{PA}_{2}$ & {$[3.76,4.52]$} & 7 & {$[0.92,1.00]$} & 7 & {$[0.84,1.00]$} & 7 & {$[0.00,0.20]$} & 7 \\
\hline $\mathrm{PA}_{3}$ & {$[2.38,3.60]$} & 4 & {$[0.59,0.70]$} & 3 & {$[0.40,0.65]$} & 4 & {$[0.40,0.65]$} & 4 \\
\hline $\mathrm{PA}_{4}$ & {$[0.60,1.56]$} & 1 & {$[0.37,0.47]$} & 1 & {$[0.00,0.20]$} & 1 & {$[0.84,1.00]$} & 1 \\
\hline $\mathrm{PA}_{5}$ & {$[2.00,2.95]$} & 3 & {$[0.58,0.75]$} & 4 & {$[0.35,0.60]$} & 3 & {$[0.60,0.86]$} & 3 \\
\hline $\mathrm{PA}_{6}$ & {$[2.62,3.53]$} & 5 & {$[0.80,0.98]$} & 5 & {$[0.60,0.86]$} & 5 & {$[0.35,0.60]$} & 5 \\
\hline $\mathrm{PA}_{7}$ & {$[3.28,4.25]$} & 6 & {$[0.86,0.99]$} & 6 & {$[0.73,0.96]$} & 6 & {$[0.15,0.44]$} & 6 \\
\hline
\end{tabular}

TABLE 7: The rough decision matrix of SA.

\begin{tabular}{lccccccc}
\hline & $\mathrm{PA}_{1}$ & $\mathrm{PA}_{2}$ & $\mathrm{PA}_{3}$ & $\mathrm{PA}_{4}$ & $\mathrm{PA}_{5}$ & $\mathrm{PA}_{6}$ & $\mathrm{PA}_{7}$ \\
\hline $\mathrm{SA}_{1}$ & {$[0.54,0.80]$} & {$[0.17,0.31]$} & {$[0.73,0.86]$} & {$[0.40,0.47]$} & {$[0.47,0.63]$} & {$[0.37,0.73]$} & {$[0.23,0.44]$} \\
$\mathrm{SA}_{2}$ & {$[0.85,1.00]$} & {$[0.59,0.65]$} & {$[0.86,0.96]$} & {$[0.47,0.60]$} & {$[0.70,0.78]$} & {$[0.65,0.82]$} & {$[0.58,0.74]$} \\
$\mathrm{SA}_{3}$ & {$[0.80,0.94]$} & {$[0.89,1.00]$} & {$[0.86,1.00]$} & {$[0.68,0.80]$} & {$[0.92,1.00]$} & {$[0.74,1.00]$} & {$[0.70,0.90]$} \\
$\mathrm{SA}_{4}$ & {$[0.00,0.00]$} & {$[0.23,0.33]$} & {$[0.00,0.00]$} & {$[0.26,0.46]$} & {$[0.34,0.40]$} & {$[0.00,0.00]$} & {$[0.00,0.00]$} \\
$\mathrm{SA}_{5}$ & {$[0.00,0.00]$} & {$[0.67,0.89]$} & {$[0.00,0.00]$} & {$[0.54,0.73]$} & {$[0.71,0.92]$} & {$[0.00,0.00]$} & {$[0.00,0.00]$} \\
$\mathrm{SA}_{6}$ & {$[0.18,0.30]$} & {$[0.00,0.00]$} & {$[0.00,0.00]$} & {$[0.73,0.86]$} & {$[0.41,0.52]$} & {$[0.00,0.00]$} & {$[0.85,1.00]$} \\
$\mathrm{SA}_{7}$ & {$[0.22,0.38]$} & {$[0.00,0.00]$} & {$[0.50,0.80]$} & {$[0.75,1.00]$} & {$[0.63,0.74]$} & {$[0.64,0.95]$} & {$[0.69,0.99]$} \\
\hline
\end{tabular}

TABLE 8: The best $f^{+}$and worst $f^{-}$of each criterion (SAs).

\begin{tabular}{llllllll}
\hline & $\mathrm{PA}_{1}$ & $\mathrm{PA}_{2}$ & $\mathrm{PA}_{3}$ & $\mathrm{PA}_{4}$ & $\mathrm{PA}_{5}$ & $\mathrm{PA}_{6}$ & $\mathrm{PA}_{7}$ \\
\hline$f_{j}^{+}$ & 1.00 & 1.00 & 1.00 & 1.00 & 1.00 & 1.00 & 1.00 \\
$f_{j}^{-}$ & 0.00 & 0.00 & 0.00 & 0.26 & 0.34 & 0.00 & 0.00 \\
\hline
\end{tabular}

rough QFD fully consider the vague and subjective evaluation of decision-makers. The fuzzy QFD is affected by the preset membership function. The interval of fuzzy number is fixed, which is determined by the types of membership functions. Moreover, the predetermination of the membership function increases additional subjective information, which can enlarge the vagueness of fuzzy number. It can be clearly seen from Figure 2 that the interval of rough number is more flexible and smaller than that of fuzzy number. For instance, the crisp ratings of the $\mathrm{CN}_{2}$ importance are $\{5,9,7,7,7\}$. The corresponding fuzzy numbers are $\{[4,6],[8,10],[6,8],[6,8],[6,8]\}$ with the fixed interval of 2 , respectively. The aggregated group fuzzy interval is $[5.9,7.9]$. This is not true in the real world, because the fuzzy method does not consider decision-makers' different knowledge and experience, and thus the fuzzy QFD considers that all the judgements have the same uncertainty (the fixed interval of 2$)$. On the contrary, the rough numbers are $\{[5.00$, $6.88],[6.88,9.00],[6.44,7.45],[6.44,7.45],[6.44,7.45]\}$ with the flexible interval, respectively. The aggregated group rough interval is $[6.20,7.61]$ which is more flexible and smaller than $[5.9,7.9]$.

Although the three methods produce the same rankings, they have different mechanisms of decision-making information manipulation. Firstly, different from the conventional
QFD, both fuzzy QFD and rough QFD consider the subjectivity and vagueness in the decision-making process. Secondly, compared with fuzzy QFD, rough QFD does not need much a priori information, for example, pre-set membership function in the fuzzy methods. More importantly, rough QFD uses flexible intervals to describe vague and subjective information, while fuzzy QFD uses fixed intervals. The weights from the former have smaller intervals than that of the latter, which indicates that the result of rough QFD is more precise. In fact, the precise weights of design attributes are important in the design decision-making process. Designers always set different threshold values of weights to determine whether the design attributes can be considered in the next stage of development. For example, $\mathrm{PA}_{2}$ will be not considered in the next stage of conventional QFD, because its weight is 0.00 . However, $\mathrm{PA}_{2}$ will be still considered in the fuzzy QFD and rough QFD, because the weights in the two methods are [0.00, $0.33]$ and $[0.00,0.20]$, respectively.

The differences of the three methods are summarized in Table 13.

\section{Conclusions}

This paper presents an improved QFD method for PRS design based on the rough set theory and VIKOR. The proposed approach uses rough VIKOR to prioritize design attributes of PRS in the vague and subjective situation. The validation of the proposed method in compressor-related service shows that it is an effective decision support tool for design of PRS. To sum up, the approach reveals the following features.

The proposed QFD method provides a progressive mapping process for PRS design. That is, mapping relationships between $\mathrm{CNs}$ and PAs and then mapping relationships 
TABLE 9: The $S, R$, and $Q$ and the weights of SAs.

\begin{tabular}{|c|c|c|c|c|c|c|c|c|}
\hline & \multicolumn{2}{|c|}{$S$} & \multicolumn{2}{|c|}{$R$} & \multicolumn{2}{|c|}{ Q } & \multirow{2}{*}{ Weight } & \multirow{2}{*}{ Rank } \\
\hline & $S_{i}$ & Rank & $R_{i}$ & Rank & $Q_{i}$ & Rank & & \\
\hline $\mathrm{SA}_{1}$ & {$[1.33,3.00]$} & 4 & {$[0.60,0.81]$} & 5 & {$[0.36,0.64]$} & 4 & {$[0.36,0.64]$} & 4 \\
\hline $\mathrm{SA}_{2}$ & {$[0.77,1.82]$} & 2 & {$[0.45,0.72]$} & 2 & {$[0.20,0.49]$} & 2 & {$[0.51,0.85]$} & 2 \\
\hline $\mathrm{SA}_{3}$ & {$[0.29,1.13]$} & 1 & {$[0.23,0.43]$} & 1 & {$[0.00,0.22]$} & 1 & {$[0.60,1.00]$} & 1 \\
\hline $\mathrm{SA}_{4}$ & {$[2.80,4.80]$} & 7 & {$[0.73,1.00]$} & 7 & {$[0.60,1.00]$} & 7 & {$[0.00,0.22]$} & 7 \\
\hline $\mathrm{SA}_{5}$ & {$[1.95,3.72]$} & 6 & {$[0.73,0.96]$} & 6 & {$[0.51,0.85]$} & 6 & {$[0.20,0.49]$} & 6 \\
\hline $\mathrm{SA}_{6}$ & {$[1.86,3.44]$} & 5 & {$[0.51,0.79]$} & 4 & {$[0.36,0.71]$} & 5 & {$[0.22,0.58]$} & 5 \\
\hline $\mathrm{SA}_{7}$ & {$[0.94,2.45]$} & 3 & {$[0.45,0.75]$} & 3 & {$[0.22,0.58]$} & 3 & {$[0.36,0.71]$} & 3 \\
\hline
\end{tabular}
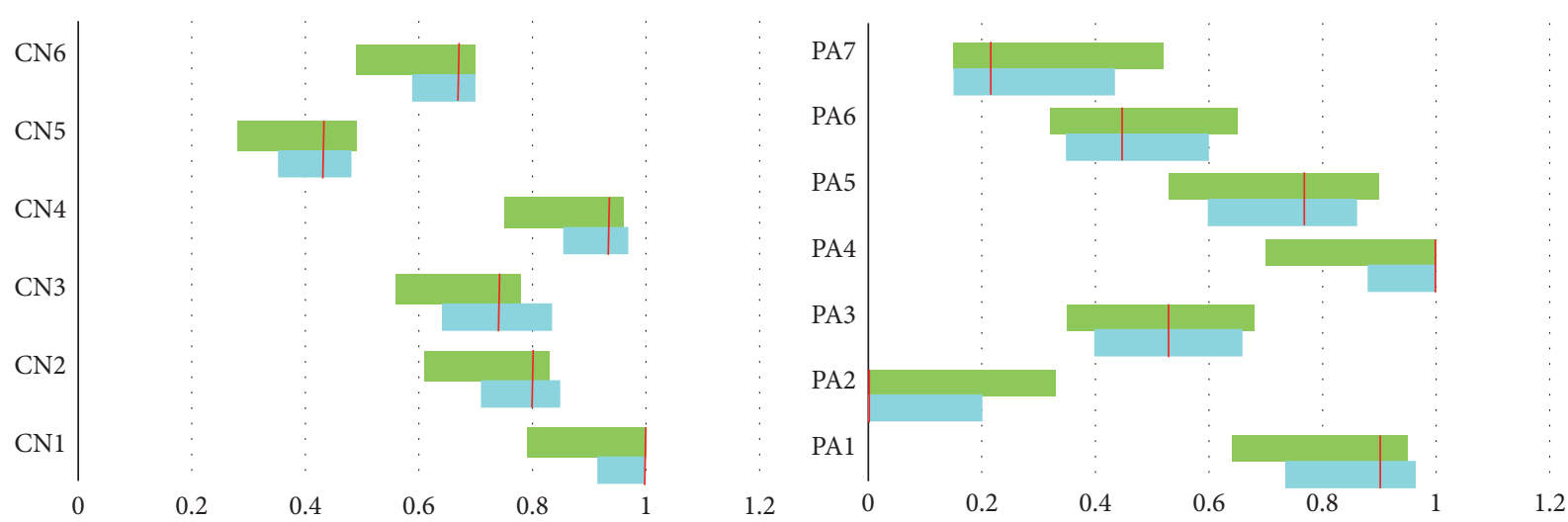

_- Crisp importance
Fuzzy importance
Rough importance

(a) Comparison of the CNs' importance

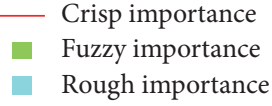

(b) Comparison of the PAs' importance

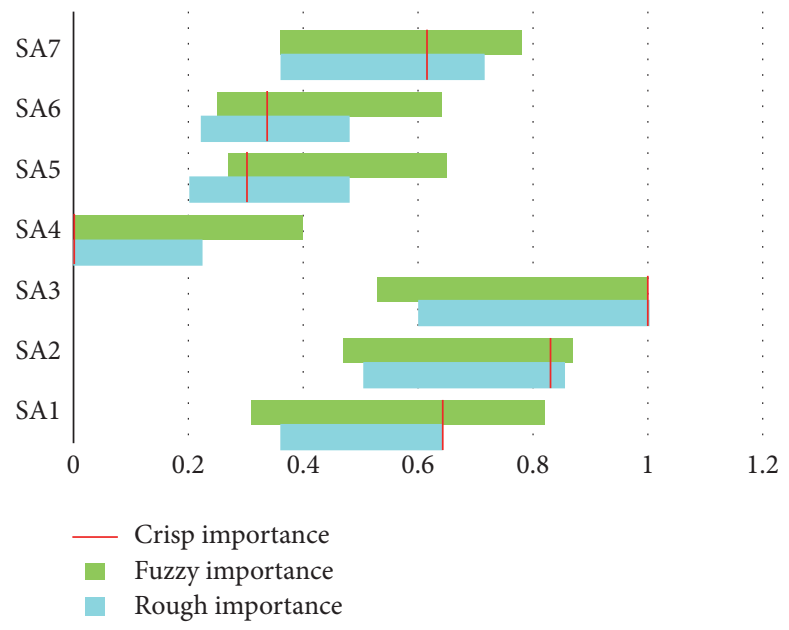

(c) Comparison of the SAs' importance

FIGURE 2: Comparison of the importance of CN, PA, and SA. 
TABLE 10: Ranking of CNs with precise, fuzzy, and rough numbers.

\begin{tabular}{ccccccc}
\hline & \multicolumn{2}{c}{ Precise } & \multicolumn{2}{c}{ Fuzzy numbers } & \multicolumn{2}{c}{ Rough numbers } \\
$\mathrm{CN}$ & \multicolumn{2}{c}{ numbers } & \multicolumn{2}{c}{ Ronk } \\
& $\omega_{i}$ & Rank & $\omega_{i}$ & Rank & $\omega_{i}$ & Rank \\
\hline $\mathrm{CN}_{1}$ & 1.00 & 1 & {$[0.79,1.00]$} & 1 & {$[0.92,1.00]$} & 1 \\
$\mathrm{CN}_{2}$ & 0.80 & 3 & {$[0.61,0.83]$} & 3 & {$[0.70,0.85]$} & 3 \\
$\mathrm{CN}_{3}$ & 0.75 & 4 & {$[0.56,0.78]$} & 4 & {$[0.63,0.83]$} & 4 \\
$\mathrm{CN}_{4}$ & 0.95 & 2 & {$[0.75,0.96]$} & 2 & {$[0.86,0.97]$} & 2 \\
$\mathrm{CN}_{5}$ & 0.43 & 6 & {$[0.28,0.49]$} & 6 & {$[0.37,0.47]$} & 6 \\
$\mathrm{CN}_{6}$ & 0.67 & 5 & {$[0.49,0.70]$} & 5 & {$[0.59,0.70]$} & 5 \\
\hline
\end{tabular}

TABLE 11: Ranking of PAs in the conventional, fuzzy, and rough QFD $(v=0.5)$.

\begin{tabular}{lcccccc}
\hline & \multicolumn{3}{c}{$\begin{array}{c}\text { Conventional } \\
\text { PA }\end{array}$} & \multicolumn{2}{c}{ QFD } & \multicolumn{2}{c}{ Quzzy QFD } & \multicolumn{2}{c}{ Rough QFD } \\
& $\omega_{j}$ & Rank & $\omega_{j}$ & Rank & $\omega_{j}$ & Rank \\
\hline $\mathrm{PA}_{1}$ & 0.92 & 2 & {$[0.64,0.95]$} & 2 & {$[0.73,0.96]$} & 2 \\
$\mathrm{PA}_{2}$ & $\mathbf{0 . 0 0}$ & 7 & {$[0.00,0.33]$} & 7 & {$[0.00,0.20]$} & 7 \\
$\mathrm{PA}_{3}$ & 0.53 & 4 & {$[0.35,0.68]$} & 4 & {$[0.40,0.65]$} & 4 \\
$\mathrm{PA}_{4}$ & 1.00 & 1 & {$[0.70,1.00]$} & 1 & {$[0.84,1.00]$} & 1 \\
$\mathrm{PA}_{5}$ & 0.78 & 3 & {$[0.53,0.90]$} & 3 & {$[0.60,0.86]$} & 3 \\
$\mathrm{PA}_{6}$ & 0.45 & 5 & {$[0.32,0.65]$} & 5 & {$[0.35,0.60]$} & 5 \\
$\mathrm{PA}_{7}$ & 0.21 & 6 & {$[0.15,0.52]$} & 6 & {$[0.15,0.44]$} & 6 \\
\hline
\end{tabular}

TABLE 12: Ranking of SAs in the conventional, fuzzy, and rough QFD $(v=0.5)$.

\begin{tabular}{lcccccc}
\hline \multirow{3}{*}{$\mathrm{SA}$} & \multicolumn{2}{c}{$\begin{array}{c}\text { QFnventional } \\
\text { QFD }\end{array}$} & \multicolumn{2}{c}{ Fuzzy QFD } & \multicolumn{2}{c}{ Rough QFD } \\
& $\omega_{j}$ & Rank & $\omega_{j}$ & Rank & $\omega_{j}$ & Rank \\
\hline $\mathrm{SA}_{1}$ & 0.64 & 4 & {$[0.31,0.82]$} & 4 & {$[0.36,0.64]$} & 4 \\
$\mathrm{SA}_{2}$ & 0.83 & 2 & {$[0.47,0.87]$} & 2 & {$[0.51,0.85]$} & 2 \\
$\mathrm{SA}_{3}$ & 1.00 & 1 & {$[0.53,1.00]$} & 1 & {$[0.60,1.00]$} & 1 \\
$\mathrm{SA}_{4}$ & $\mathbf{0 . 0 0}$ & 7 & {$[0.00,0.40]$} & 7 & {$[0.00,0.22]$} & 7 \\
$\mathrm{SA}_{5}$ & 0.29 & 6 & {$[0.27,0.65]$} & 6 & {$[0.20,0.49]$} & 6 \\
$\mathrm{SA}_{6}$ & 0.35 & 5 & {$[0.25,0.64]$} & 5 & {$[0.22,0.58]$} & 5 \\
$\mathrm{SA}_{7}$ & 0.61 & 3 & {$[0.36,0.78]$} & 3 & {$[0.36,0.71]$} & 3 \\
\hline
\end{tabular}

between PAs and SAs, which is not presented in previous literature of PRS. PRS designers can systematically make reasonable planning of product and service in the early design of PRS.

RN with flexible boundary is used to manipulate the vagueness and subjectivity in the QFD analysis process to reduce lost information, because it can comprehensively reflect decision-maker's subjective judgment and preference.

The rough VIKOR provides a structured framework of compromise decision-making in PRS design under vague and subjective environment.

The proposed approach for PRS planning can be implemented without large amount of data and much a priori information (e.g., pre-set membership function).
TABLE 13: Main differences between the rough QFD, conventional QFD, and fuzzy QFD.

\begin{tabular}{lccc}
\hline Method & $\begin{array}{c}\text { Manipulation of } \\
\text { uncertainty }\end{array}$ & $\begin{array}{c}\text { Reliance on much } \\
\text { prior information }\end{array}$ & Flexibility \\
\hline Conventional & No & No & Low \\
QFD & Partial & Yes & Low \\
Fuzzy QFD & Yes & No & High \\
Rough QFD & & & \\
\hline
\end{tabular}

Although the rough VIKOR-based QFD has merits in dealing with vagueness and subjectivity, it does not consider different weights of decision-makers in the QFD group. Therefore, to better reflect the actual situation of decisionmaking in QFD implementation process, it is necessary to develop suitable aggregation operators for judgments aggregation. The aggregation operators' influence on the rough VIKOR-based QFD would also be explored in future researches. Besides, more testing work is necessitated to gain external validity.

\section{Competing Interests}

The authors declare that there are no competing interests regarding the publication of this paper.

\section{Acknowledgments}

The work described in this paper was supported by the National Natural Science Foundation of China (Grant no. 71501006). It was also partially supported by the National Natural Science Foundation of China (Grants nos. 71332003, 71632003, and 71420107025) and the Fundamental Research Funds for the Central Universities.

\section{References}

[1] Magnusson and R. Peter, Customer-Oriented Product Development: Experiments Involving Users in Service Innovation, 2003.

[2] M. A. Cusumano, The Business of Software, Free Press/Simon \& Schuster, Cambridge, Mass, USA, 2004.

[3] W. Song, Z. Wu, X. Li, and Z. Xu, "Modularizing product extension services: an approach based on modified service blueprint and fuzzy graph," Computers and Industrial Engineering, vol. 85, pp. 186-195, 2015.

[4] W. Song and F. T. S. Chan, "Multi-objective configuration optimization for product-extension service," Journal of Manufacturing Systems, vol. 37, pp. 113-125, 2015.

[5] T. S. Baines, H. W. Lightfoot, S. Evans et al., "State-of-the-art in product-service systems," Proceedings of the Institution of Mechanical Engineers Part B: Journal of Engineering Manufacture, vol. 221, no. 10, pp. 1543-1552, 2007.

[6] Y. Akao, Quality Function Deployment: Integrating Customer Requirements into Product Design, Productivity Press, Cambridge, Mass, USA, 1990.

[7] C.-T. Wu, T.-S. Pan, M.-H. Shao, and C.-S. Wu, "An extensive QFD and evaluation procedure for innovative design," Mathematical Problems in Engineering, vol. 2013, Article ID 935984, 7 pages, 2013. 
[8] M. Li, "The method for product design selection with incomplete linguistic weight information based on quality function deployment in a fuzzy environment," Mathematical Problems in Engineering, vol. 2013, Article ID 943218, 10 pages, 2013.

[9] S. Yang, J. Liu, K. Wang, and Y. Miao, "An uncertain QFD approach for the strategic management of logistics services," Mathematical Problems in Engineering, vol. 2016, Article ID 1486189, 10 pages, 2016.

[10] C.-Y. Tsai, C.-C. Lo, and A. C. Chang, "Using fuzzy QFD to enhance manufacturing strategic planning," Journal of the Chinese Institute of Industrial Engineers, vol. 20, no. 1, pp. 3341, 2003.

[11] L.-H. Chen and M.-C. Weng, "An evaluation approach to engineering design in $\mathrm{QFD}$ processes using fuzzy goal programming models," European Journal of Operational Research, vol. 172, no. 1, pp. 230-248, 2006.

[12] Y. An, S. Lee, and Y. Park, "Development of an integrated product-service roadmap with QFD: a case study on mobile communications," International Journal of Service Industry Management, vol. 19, no. 5, pp. 621-638, 2008.

[13] Y. Lin and S. Pekkarinen, "QFD-based modular logistics service design," Journal of Business and Industrial Marketing, vol. 26, no. 5, pp. 344-356, 2011.

[14] J. A. Fitzsimmons and M. J. Fitzsimmons, Service Management: Operations, Strategy, and Information Technology, Irwin/McGraw-Hill, 2006.

[15] H. Li, Y. Ji, X. Gu, G. Qi, and R. Tang, "Module partition process model and method of integrated service product," Computers in Industry, vol. 63, no. 4, pp. 298-308, 2012.

[16] Y. Geum, R. Kwak, and Y. Park, "Modularizing services: a modified HoQ approach," Computers \& Industrial Engineering, vol. 62, no. 2, pp. 579-590, 2012.

[17] W. J. Selen and J. Schepers, "Design of quality service systems in the public sector: use of quality function deployment in police services," Total Quality Management, vol. 12, no. 5, pp. 677-687, 2001.

[18] Y.-T. Chen and T.-Y. Chou, "Applying GRA and QFD to improve library service quality," The Journal of Academic Librarianship, vol. 37, no. 3, pp. 237-245, 2011.

[19] H.-Y. Wu and H.-Y. Lin, "A hybrid approach to develop an analytical model for enhancing the service quality of elearning," Computers and Education, vol. 58, no. 4, pp. 13181338, 2012.

[20] X. Geng, X. Chu, D. Xue, and Z. Zhang, "A systematic decisionmaking approach for the optimal product-service system planning," Expert Systems with Applications, vol. 38, no. 9, pp. 1184911858, 2011.

[21] W. Song, X. Ming, and Y. Han, "Prioritising technical attributes in QFD under vague environment: a rough-grey relational analysis approach," International Journal of Production Research, vol. 52, no. 18, pp. 5528-5545, 2014.

[22] C.-T. Su and C.-S. Lin, "A case study on the application of fuzzy QFD in TRIZ for service quality improvement," Quality and Quantity, vol. 42, no. 5, pp. 563-578, 2008.

[23] E. Bottani, "A fuzzy QFD approach to achieve agility," International Journal of Production Economics, vol. 119, no. 2, pp. 380391, 2009.

[24] J.-F. Ding, "Applying fuzzy quality function deployment (QFD) to identify solutions of service delivery system for port of Kaohsiung," Quality \& Quantity, vol. 43, no. 4, pp. 553-570, 2009.
[25] L.-Y. Zhai, L.-P. Khoo, and Z.-W. Zhong, "A rough set enhanced fuzzy approach to quality function deployment," The International Journal of Advanced Manufacturing Technology, vol. 37, no. 5-6, pp. 613-624, 2008.

[26] L. C. Jain, Knowledge Based Intelligent Techniques in Industry, vol. 1, CRC Press, New York, NY, USA, 1999.

[27] Z. Pawlak, "Rough sets," International Journal of Computer \& Information Sciences, vol. 11, no. 5, pp. 341-356, 1982.

[28] Z. Pawlak, Rough Sets: Theoretical aspects of Reasoning about Data, Kluwer Academic, Dordrecht, The Netherlands, 1991.

[29] L. P. Khoo, S. B. Tor, and L. Y. Zhai, "Rough-set-based approach for classification and rule induction," The International Journal of Advanced Manufacturing Technology, vol. 15, no. 6, pp. 438444, 1999.

[30] C. Lee, H. Lee, H. Seol, and Y. Park, "Evaluation of new service concepts using rough set theory and group analytic hierarchy process," Expert Systems with Applications, vol. 39, no. 3, pp. 3404-3412, 2012.

[31] S. Opricovic, "Multicriteria optimization of civil engineering systems," Faculty of Civil Engineering, Belgrade, vol. 2, no. 1, pp. 5-21, 1998.

[32] S. Opricovic and G.-H. Tzeng, "Compromise solution by MCDM methods: a comparative analysis of VIKOR and TOPSIS," European Journal of Operational Research, vol. 156, no. 2, pp. 445-455, 2004.

[33] S. Opricovic and G.-H. Tzeng, "Extended VIKOR method in comparison with outranking methods," European Journal of Operational Research, vol. 178, no. 2, pp. 514-529, 2007.

[34] A. Griffin and J. R. Hauser, "The voice of the customer," Marketing Science, vol. 12, no. 1, pp. 1-27, 1993.

[35] C. K. Kwong and H. Bai, "Determining the importance weights for the customer requirements in QFD using a fuzzy AHP with an extent analysis approach," IIE Transactions, vol. 35, no. 7, pp. 619-626, 2003.

[36] N. Kano, N. Seraku, F. Takahashi, and S. Tsuji, "Attractive quality and must-be quality, Hinshitsu," The Journal of the Japanese Society for Quality Control, vol. 14, no. 2, pp. 39-48, 1984.

[37] A. H. Maslow, "A theory of human motivation," Psychological Review, vol. 50, no. 4, pp. 370-396, 1943.

[38] W. Song, X. Ming, Y. Han, and Z. Wu, "A rough set approach for evaluating vague customer requirement of industrial productservice system," International Journal of Production Research, vol. 51, no. 22, pp. 6681-6701, 2013.

[39] S. Liao, M.-J. Wu, C.-Y. Huang, Y.-S. Kao, and T.-H. Lee, "Evaluating and enhancing three-dimensional printing service providers for rapid prototyping using the DEMATEL based network process and VIKOR," Mathematical Problems in Engineering, vol. 2014, Article ID 349348, 16 pages, 2014. 


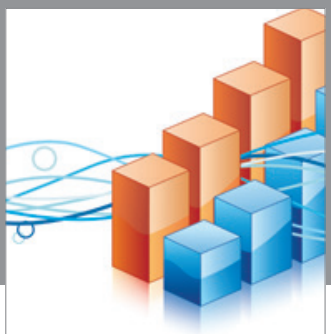

Advances in

Operations Research

vatem alat4

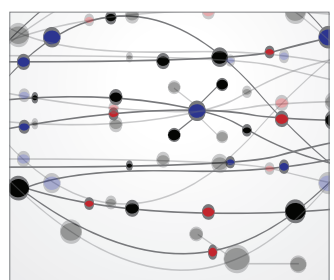

\section{The Scientific} World Journal
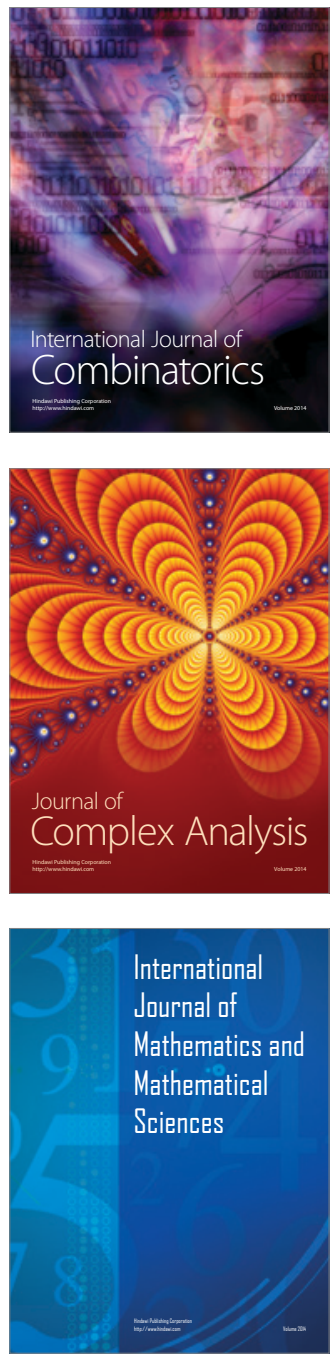
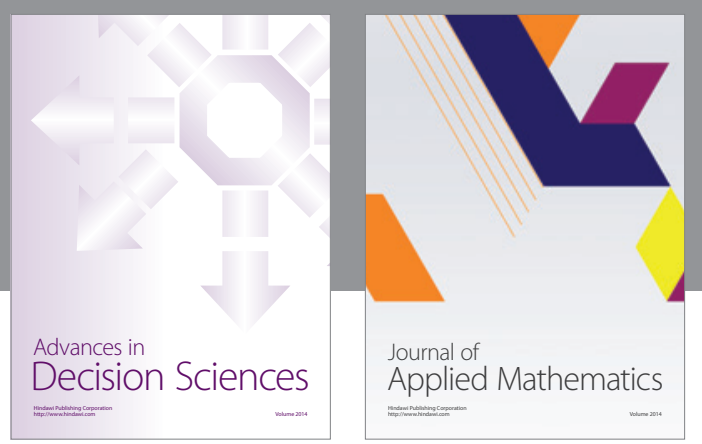

Algebra

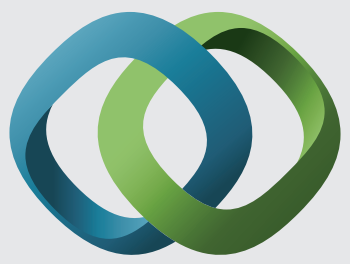

\section{Hindawi}

Submit your manuscripts at

http://www.hindawi.com
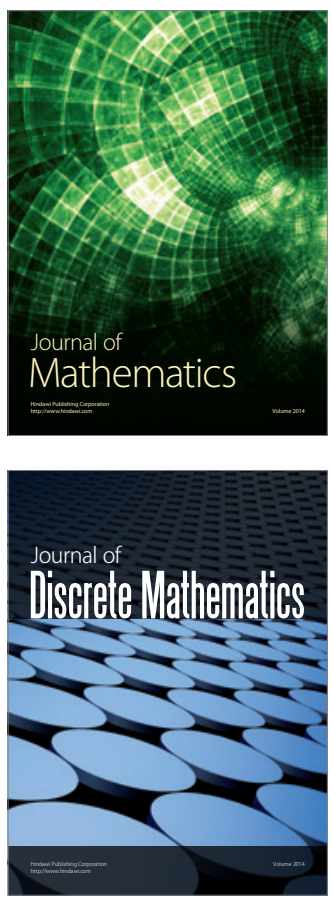

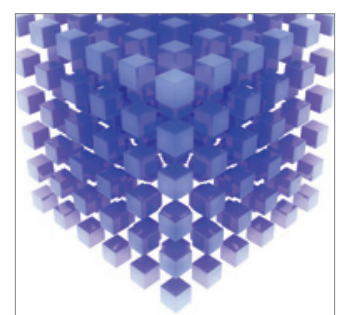

Mathematical Problems in Engineering
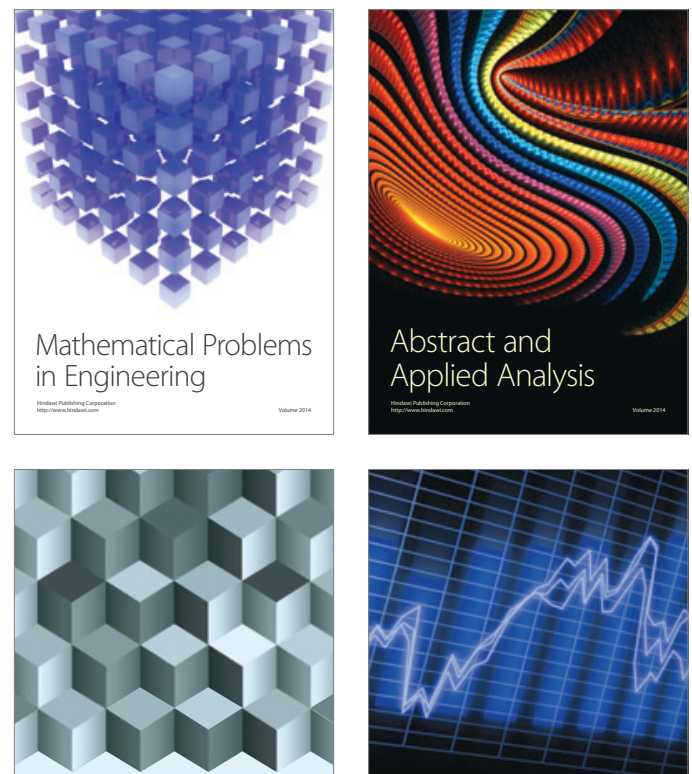

Journal of

Function Spaces

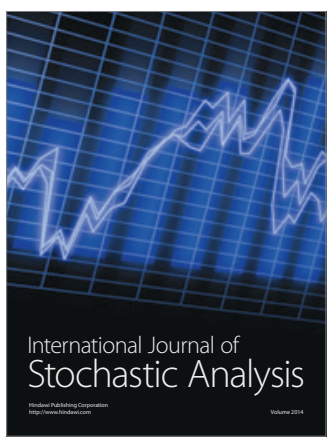

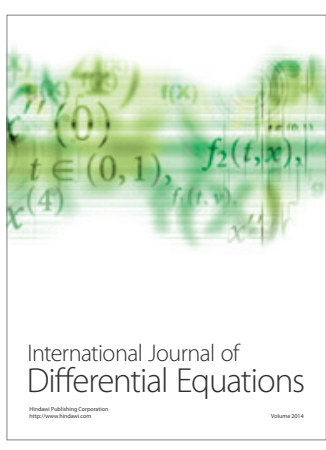
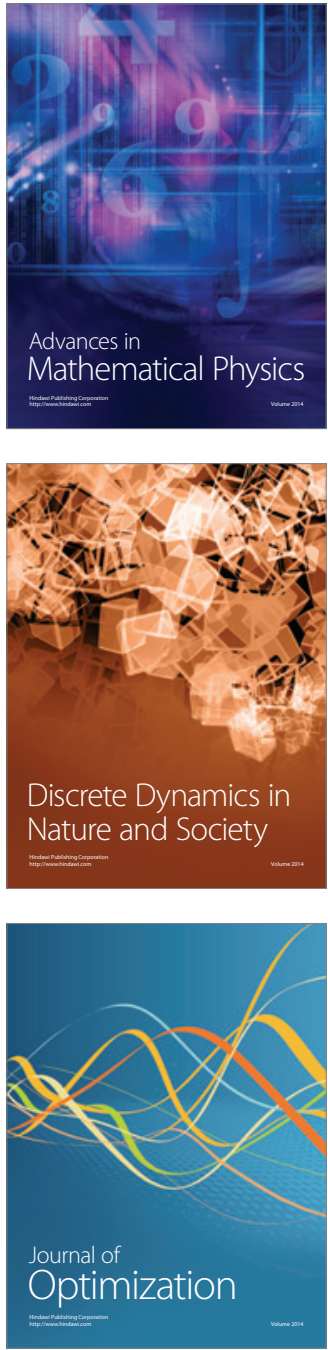